\title{
A Novel Lateral Approach to the Assessment of Vocal Cord Movement by Ultrasonography
}

\author{
Takahiro Fukuhara $^{1} \cdot$ Ryohei Donishi $^{1} \cdot$ Eriko Matsuda $^{1} \cdot$ Satoshi Koyama $^{1} \cdot$ \\ Kazunori Fujiwara $^{1} \cdot$ Hiromi Takeuchi $^{1}$
}

Published online: 27 July 2017

(C) The Author(s) 2017. This article is an open access publication

\begin{abstract}
Background Ultrasonography is a non-invasive technique that is commonly used by endocrinologists and endocrine surgeons to examine the thyroid region and could be useful for the assessment of vocal cord movement by these specialists. However, previous studies reported a low rate of successful visualization of vocal cord movement by ultrasonography. To address this issue, we devised a novel ultrasonographic procedure for assessing vocal cord movement indirectly by observing the arytenoid movement from a lateral view.

Methods Subjects were 188 individuals, including 23 patients with vocal cord paralysis and 13 with vocal cord paresis. We performed ultrasonographic assessment of vocal cord movement using two different procedures: the conventional middle transverse procedure and the novel lateral vertical procedure.

Results The rate of visualization of vocal cords with the middle transverse procedure was $70.2 \%$ and that of the arytenoid cartilage with the lateral vertical procedure was $98.4 \%$. The lateral vertical procedure enabled visualization of all patients with vocal cord paresis/paralysis and detected all 23 patients with vocal paralysis; only one of 13 patients with vocal cord paresis was positively identified. The conventional procedure enabled visualization of 21 of 36 patients with vocal cord paresis/paralysis with high accuracy. There was no false-positive case in either procedure. Conclusion The proposed lateral vertical procedure improved the rate of visualization of vocal cord movement by ultrasonography, suggesting that it is a useful technique to screen for vocal cord paralysis by ultrasonography.
\end{abstract}

\section{Introduction}

Vocal cord paralysis caused by recurrent nerve palsy is a major complication of thyroid surgery [1-3]. Therefore, it is important for endocrinologists and endocrine surgeons to assess vocal cord movement. The gold standard procedure

Electronic supplementary material The online version of this article (doi:10.1007/s00268-017-4151-z) contains supplementary material, which is available to authorized users.

Takahiro Fukuhara

tfukuhara3387@med.tottori-u.ac.jp

1 Department of Otolaryngology, Head and Neck Surgery, Tottori University Faculty of Medicine, 36-1 Nishicho, Yonago 683-8504, Japan for assessing vocal cord movement is flexible nasopharyngoscopy. However, nasopharyngoscopy is partly invasive [4] and not commonly performed by endocrinologists or endocrine surgeons [5]. On the other hand, ultrasonography is non-invasive and is commonly used by these specialists for surveys of the neck [6]. Therefore, ultrasonography would be a useful tool for the assessment of vocal cord movement by these clinicians.

Several studies have described ultrasonographic assessment of vocal cord paralysis. However, the rate of successful visualization of vocal cord movement by ultrasonography is lower than that achieved by nasopharyngoscopy; consequently, ultrasonography is not considered an adequate alternative tool [7]. The visualization rate is reported to be approximately 50\% [8]. The 
low visualization rate was attributed to the calcification or angle of the thyroid cartilage [7, 9]. In addition, previous studies used procedures in which they directly observed the vocal cord surrounded by air [8, 10-14].

We devised a novel ultrasonographic procedure for assessing vocal cord movement by observing the arytenoid movement from a lateral view. This novel procedure is based on the indirect assessment of vocal cord movement by observing the movement of the arytenoid cartilage through the shortest distance. The arytenoids are surrounded by tissues without air and can therefore be observed easily, whereas the true vocal cords are surrounded by air. Therefore, this novel procedure is expected to improve the visualization rate for assessing vocal cord movement. This study verified the usefulness of the proposed ultrasonographic procedure for assessing vocal cord movement.

\section{Patients and methods}

\section{Patients}

Vocal cord movement was assessed in patients who received cervical ultrasonography for screening or further evaluation (Table 1) and who underwent nasopharyngoscopy within 6 months of ultrasonography. A total of 188 consecutive patients were enrolled between September 2013 and April 2014. The study was approved by the Institutional Review Board of Tottori University and was performed in accordance with the Declaration of Helsinki.

\section{Measurement procedures}

We used an ACUSON S2000 ultrasound system with a 9-MHz linear transducer (Siemens Medical Solutions USA). We performed ultrasonographic assessment of vocal cord movement using two different procedures in conjunction with cervical ultrasonographic examination.

The patients underwent cervical ultrasonographic examination in the supine position with their neck slightly extended and at the end of the examination underwent ultrasonographic assessment of vocal cord movement by two different procedures in the same position. In one of the procedures, we placed the linear transducer transversely over the middle portion of the thyroid cartilage and observed the bilateral vocal cords bounded by air (Fig. 1). In the other procedure, the transducer was placed vertically at $1-1.5 \mathrm{~cm}$ inside and parallel to the lateral border, along the oblique line of the thyroid cartilage because the arytenoid cartilage is located behind the oblique line of the thyroid cartilage (Fig. 2). The transducer was placed at the right and left sides of the thyroid cartilage lamina, and the movement of the right and left arytenoid cartilages was observed separately (Fig. 3).
Table 1 Clinical characteristics of the subjects

\begin{tabular}{|c|c|c|}
\hline Total number & & 188 \\
\hline \multirow[t]{2}{*}{ Gender } & Male & 89 \\
\hline & Female & 99 \\
\hline Age (average) & & $63.4 \pm 15.1$ \\
\hline \multirow[t]{3}{*}{ Vocal palsy on laryngoscopy } & No & 152 \\
\hline & Paresis & 13 \\
\hline & Paralysis & 23 \\
\hline \multirow{2}{*}{$\begin{array}{l}\text { Gender of the patients with vocal } \\
\text { palsy }\end{array}$} & Male & 21 \\
\hline & Female & 15 \\
\hline $\begin{array}{l}\text { Age of the patients with vocal } \\
\text { palsy (average) }\end{array}$ & & $70.5 \pm 9.8$ \\
\hline \multirow[t]{15}{*}{ Primary disease } & Thyroid disease & \\
\hline & $\begin{array}{l}\text { Malignant } \\
\text { tumor }\end{array}$ & 52 \\
\hline & Benign tumor & 10 \\
\hline & $\begin{array}{l}\text { Adenomatous } \\
\text { goiter }\end{array}$ & 32 \\
\hline & $\begin{array}{l}\text { Autoimmune } \\
\text { thyroiditis }\end{array}$ & 6 \\
\hline & $\begin{array}{l}\text { Parathyroid } \\
\text { tumor }\end{array}$ & 5 \\
\hline & $\begin{array}{l}\text { Head and neck } \\
\text { tumor }\end{array}$ & \\
\hline & $\begin{array}{l}\text { Malignant } \\
\text { tumor }\end{array}$ & 42 \\
\hline & Benign tumor & 2 \\
\hline & Cyst & 4 \\
\hline & Lymph node & \\
\hline & $\begin{array}{l}\text { Malignant } \\
\text { Lymphoma }\end{array}$ & 2 \\
\hline & Lymphadenitis & 11 \\
\hline & Globus & 10 \\
\hline & Others & 12 \\
\hline
\end{tabular}

In our hospital, otolaryngologists classify vocal cord movements into three groups based on the results of nasopharyngoscopy: normal, paresis, and paralysis. However, in ultrasonography, bilateral true vocal cord visualization is considered an indicator of the successful performance of the middle transverse procedure, whereas arytenoid visualization indicates a successful lateral vertical procedure. The criterion for the positive detection of vocal cord paresis/paralysis using the middle transverse procedure was asymmetric abduction and adduction movements of the true vocal cords. However, simultaneous observation of the right and left sides was not possible in the lateral vertical procedure, and we were unable to compare ultrasound images between the two sides. Therefore, the positive diagnostic criterion for vocal cord paralysis in the lateral vertical procedure was fixation of the arytenoid cartilage to avoid subjectivity (Fig. 4).

First, the percentages of visible true vocal cords or arytenoid cartilages were compared between the two 
Fig. 1 a Probe placed transversely over the middle portion of the thyroid cartilage. b Ultrasonographic view showing a normal visualized case. True vocal cord (arrowhead); arytenoid cartilage (arrow)

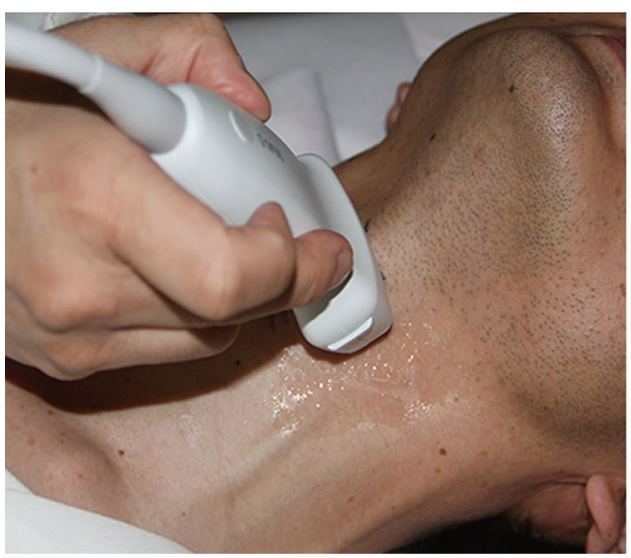

a

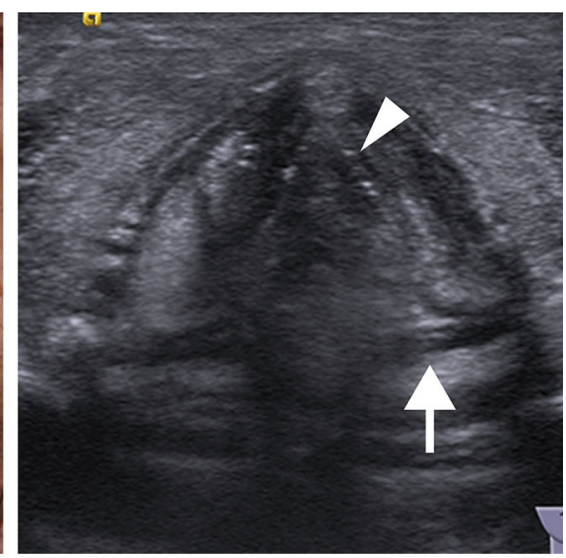

b

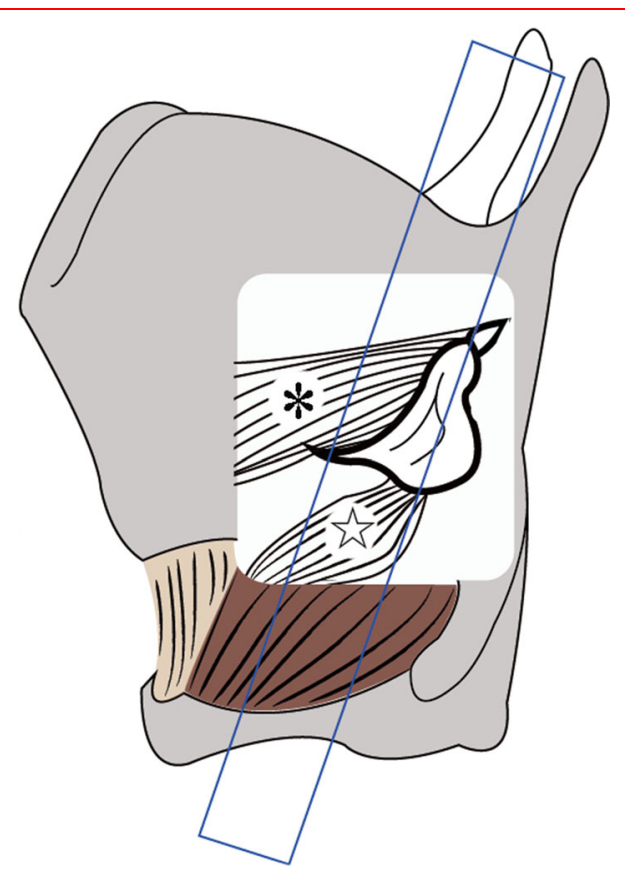

Fig. 2 Inner structures of the larynx visualized through the window of larynx by ultrasonography with the lateral procedure. Arytenoid cartilage (arrow); *, thyroarytenoid muscle; is, lateral cricoarytenoid muscle

procedures. Then, the results of the evaluation of vocal cord movement by ultrasonography were confirmed for each procedure based on the results of nasopharyngoscopy.

\section{Statistical analysis}

Statistical analyses were performed using SPSS software (IBM SPSS Statistics 22; IBM, Japan). The percentages of visible true vocal cords or arytenoid cartilages were compared between the two procedures using the McNemar test.

\section{Results}

The characteristics of the 188 subjects, including 23 patients with vocal cord paralysis and 13 patients with vocal cord paresis, are shown in Table 2.

The visualization rate of vocal cords with the middle transverse procedure was $70.2 \%$ (assessable, 132; nonassessable, 56), and the visualization rate of arytenoid cartilage with the lateral vertical procedure was $98.4 \%$ (assessable, 185; non-assessable, 3). In fact, arytenoid cartilages were not visualized in only three patients. The visualization rate was significantly higher with the lateral vertical procedure than with the middle transverse procedure $(P<0.001)$.

The results of the evaluation of vocal cord movement by ultrasonography with each procedure were compared with those obtained by nasopharyngoscopy (Table 2). In each group, some cases were not assessable with the middle transverse procedure; however, for the visualized cases, this procedure was highly accurate. On the other hand, the accuracy of evaluation of vocal cord paresis by the novel lateral vertical procedure was low, and all of the falsenegative cases involved vocal cord paresis. There were no false-positive cases in either of the procedures.

\section{Discussion}

It is important for endocrinologists and endocrine surgeons to determine whether the vocal cords are paralyzed. The gold standard for assessing vocal cord paralysis is nasopharyngoscopy; however, this technique is ordinarily used by otolaryngologists. On the other hand, ultrasonography is commonly used by endocrinologists and endocrine surgeons to examine the thyroid region [6]. Therefore, assessment of vocal cord movement by ultrasonography would be efficient and economical [15]. Several studies over the past two 
Fig. 3 a Probe placed vertically along the left lamina of the thyroid cartilage.

b Ultrasonographic view of the lateral vertical procedure. Muscular process of the arytenoid cartilage (arrow); *, thyroarytenoid muscle; $i$, lateral cricoarytenoid muscle

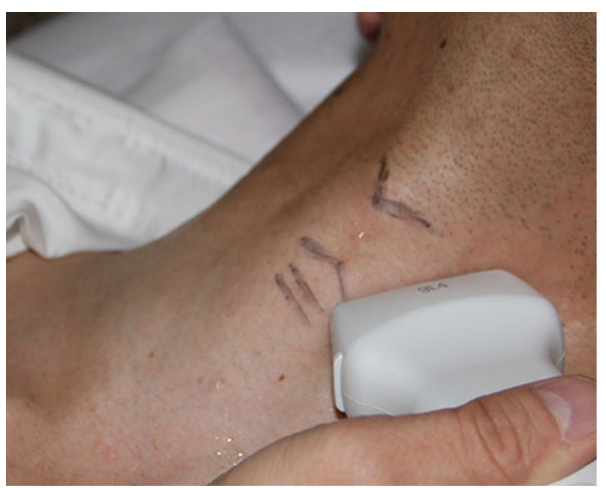

a

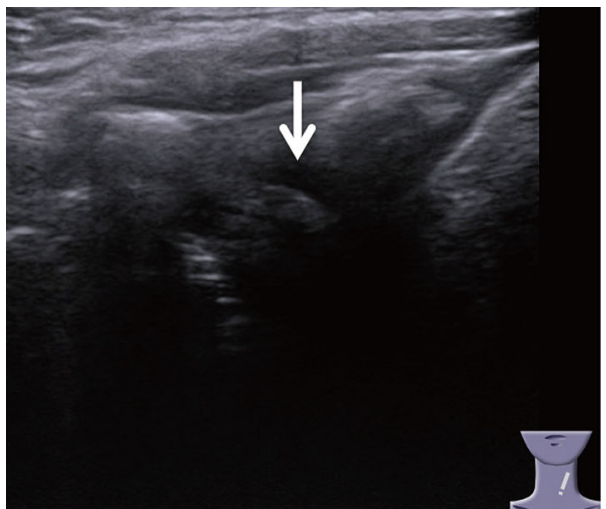

a

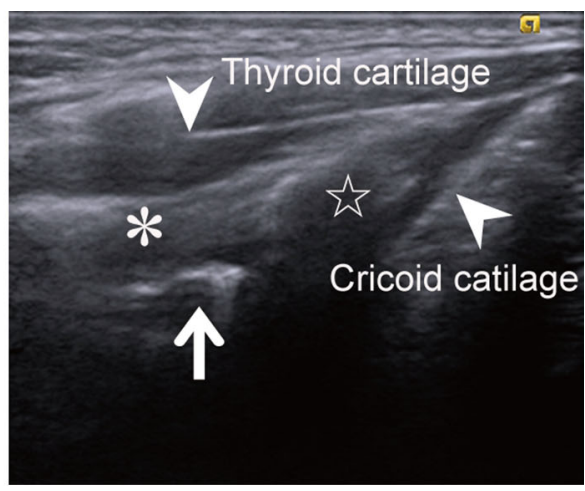

b

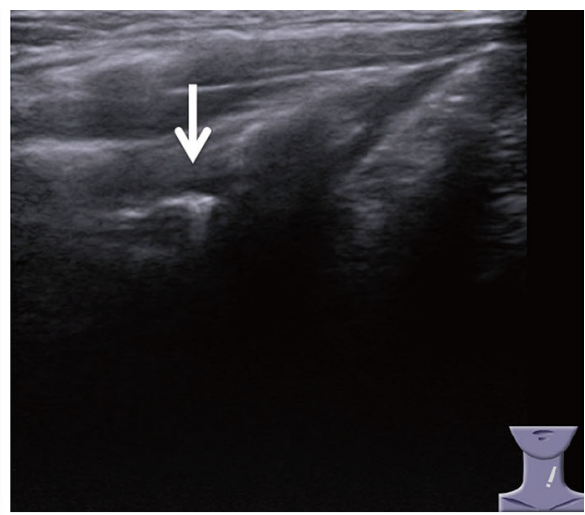

b

Table 2 Results of ultrasonographic evaluation of vocal cord movement with each procedure

\begin{tabular}{|c|c|c|c|c|}
\hline & & Normal & Paresis & Paralysis \\
\hline \multirow[t]{4}{*}{ Conventional middle transverse procedure } & Non-assessable & 41 & 6 & 9 \\
\hline & Positive & 0 & 6 & 14 \\
\hline & Negative & 111 & 1 & 0 \\
\hline & Total & 152 & 13 & 23 \\
\hline \multirow[t]{4}{*}{ Novel lateral vertical procedure } & Non-assessable & 3 & 0 & 0 \\
\hline & Positive & 0 & 1 & 23 \\
\hline & Negative & 149 & 12 & 0 \\
\hline & Total & 152 & 13 & 23 \\
\hline
\end{tabular}

decades have described the use of ultrasonography to assess the vocal cords $[16,17]$. Initially, ultrasonography was not sufficient for clinically useful observation. Owing to technological innovations; however, it has recently become easy to visualize the vocal folds from the body surface [18]. However, the success rates of observing vocal cord movement in these studies varied widely, and ultrasonography is still not thought to be a sufficiently precise tool to assess vocal cord movement [8, 10-14].
These previous reports shared a common feature, namely that they observed the vocal cords directly by the middle transverse procedure. However, this procedure has the notable disadvantage that it is easily influenced by the calcification or angle of the thyroid cartilage [7, 9]. Additionally, we suspected that the main factor responsible for the low rate of successful visualization of vocal cords is the poor ultrasonic permeability of air (Fig. 5). 


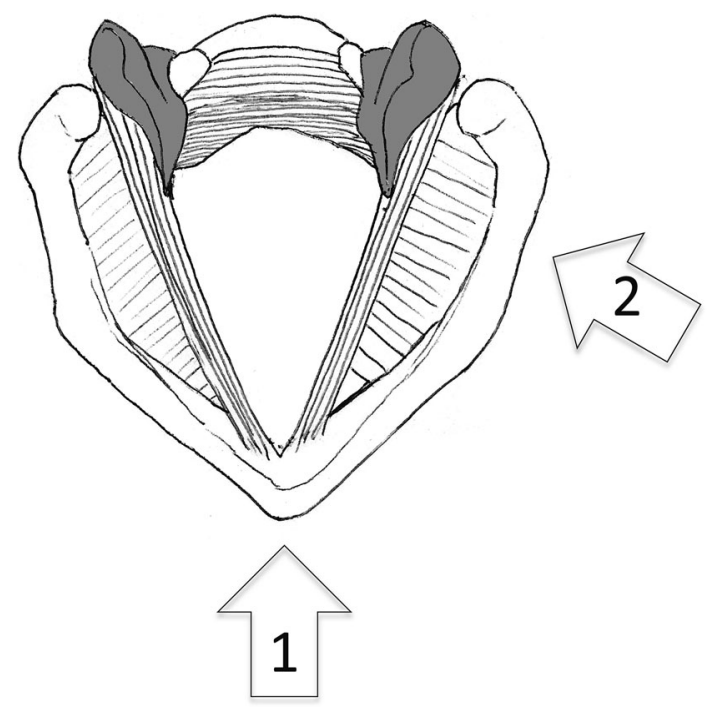

Fig. 5 Arytenoid cartilages are colored in gray. 1 The middle approach. 2 The lateral approach

Many past studies using the middle transverse procedure that defined success as bilateral true vocal cord visualization reported visualization rates of $70-87 \%$ [10-14]. The variation in this rate may have been caused by differences in the proportion of women, because visualization rates were much higher in women than in men [10-14]. In this study, the true vocal cords were the targets of observation with the middle transverse procedure, because the true vocal cords directly reflect the function of the recurrent nerve. Our visualization rate with the middle transverse procedure was similar to that reported in previous studies.

Some studies reported very high visualization rates, around $95 \%[7,9,19-21]$, but in these cases the authors defined visualization of one of three landmarks (true vocal cord, false vocal cord, or arytenoid cartilage) as success. These authors reported that visualization rate of false vocal fold was much higher than that of true vocal cord. The arytenoid cartilage is one of the landmarks for assessing vocal cord movement; however, it is difficult to generate a clear ultrasonographic image of the arytenoid cartilage using the middle transverse procedure because of its deep position.

Woo et al. [22] described the lateral approach for assessment of vocal cord movement. This procedure, which involves direct transverse observation of the vocal cord, had a very high visualization rate. However, it is difficult to create a good view of the transverse vocal cord and requires mastery of the technique. Furthermore, the vocal cords shift in a cranial direction during phonation, making it difficult to observe the vocal cords transversely during phonation.

On the other hand, it was easy to create an image using our lateral vertical procedure for observing movement of

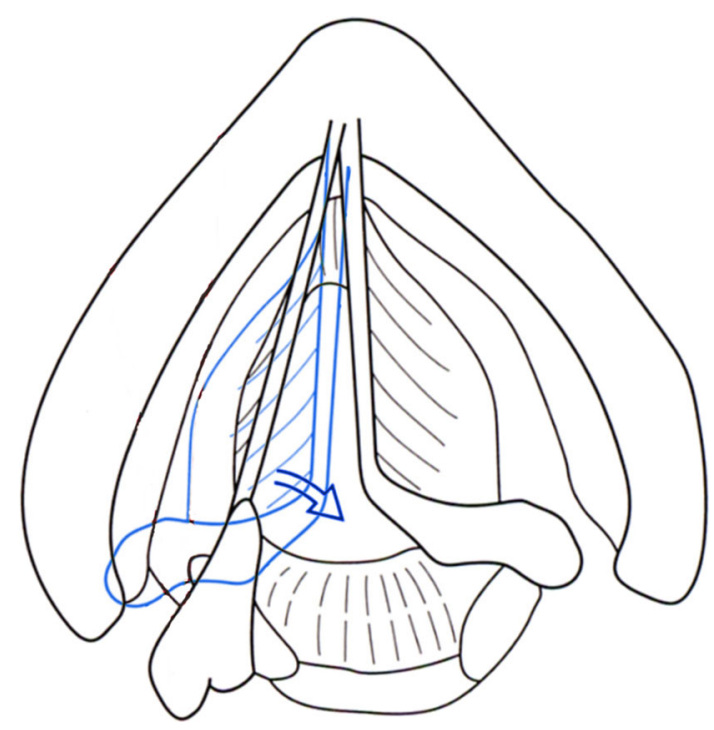

Fig. 6 Movement of the arytenoid cartilage during phonation

the arytenoid cartilage. In the studies cited above, the visualization rate of arytenoid cartilage was high $[1-3,7]$. Because the vocal ligament and muscle connect the vocal process and oblong fovea of the arytenoid cartilage, vocal cord movement can be assessed by evaluating movement of the arytenoid cartilage (Fig. 6). When we observe this movement, we can see a dynamic motion in the vertical view because the arytenoid cartilage rotates three-dimensionally just behind the thyroid cartilage. In the surgical procedure (the fenestration approach) for arytenoid adduction, the arytenoid cartilage is accessed through a hole in the lamina of the thyroid cartilage [23, 24]. This surgical procedure demonstrates that the arytenoid cartilage is close to the lamina of thyroid cartilage. In addition, the arytenoid cartilage can be accessed without tearing the pharyngeal mucosa during the procedure. This allows observation of the arytenoid cartilage using a lateral approach and bypassing the air of the laryngopharyngeal space.

We believe that these features explain why the visualization rate of our procedure was superior to that of the conventional middle transverse procedure, and the diagnostic accuracy of our procedure was higher than the conventional procedure.

The lateral approach had its own limitation; namely, the examiners had to perform non-synchronous observation of right and left vocal cord movements. Non-synchronous observation required more time than synchronous observation, and it was difficult to detect minor differences in the vocal cord movement between the right and left sides. Furthermore, in our lateral procedure, we judged vocal cord paresis/paralysis not based on a reduction in movement, but 
instead based on fixation of the muscular process of the arytenoid cartilage. Consequently, our procedure may be unsuitable for evaluation of vocal cord paresis. However, vocal cord paresis can include a wide range of vocal cord movement: some cases exhibit approximately normal movement, whereas others approximate paralysis. In this study, the only case of vocal cord paresis identified by our lateral vertical procedure was a case of approximate paralysis.

Minor vocal cord paresis is difficult to detect despite the use of nasopharyngoscopy, even for specialists in otolaryngology [25]. Therefore, the need to detect minor vocal paresis by ultrasonography is debatable. However, in cases of vocal cord paresis resulting from thyroid cancer invasion or other causes that require further evaluation, nasopharyngoscopy is the preferred method to evaluate vocal cord movement. Recently developed ultrasonographic systems use a dual-window view, with one window showing a realtime image while the other window plays a recorded movie. Such a system enables comparison of vocal cord movements on the right and left sides in a synchronous manner.

Our lateral vertical procedure is a logical method for approaching inner larynx and improved the visualization rate of vocal cord movement by ultrasonography. We conclude that our novel procedure is useful for ultrasonographic assessment of vocal cord movement, which could be used to screen for vocal cord paralysis.

Acknowledgements This work was supported by JSPS KAKENHI Grant Number 16K20246.

\section{Compliance with ethical standards}

Conflict of interest The authors declare that no competing financial interests exist.

Open Access This article is distributed under the terms of the Creative Commons Attribution 4.0 International License (http://creative commons.org/licenses/by/4.0/), which permits unrestricted use, distribution, and reproduction in any medium, provided you give appropriate credit to the original author(s) and the source, provide a link to the Creative Commons license, and indicate if changes were made.

\section{References}

1. Sugitani S, Fujimoto Y (1999) Symptomatic versus asymptomatic papillary thyroid microcarcinoma: a retrospective analysis of surgical outcome and prognostic factors. Endocr J 46:209-216

2. Ozbas S, Kocak S, Aydintug S et al (2005) Comparison of the complications of subtotal, near total and total thyroidectomy in the surgical management of multiple goiter. Endocr J 52:199-205

3. Randolph GW, Kamani D (2006) The importance of preoperative laryngoscopy in patients undergoing thyroidectomy: voice, vocal cord function, and the preoperative detection of invasive thyroid malignancy. Surgery 139:357-362
4. Paul BC, Rafii B, Achlatis S et al (2012) Morbidity and patient perception of flexible laryngoscopy. Ann Otol Rhinol Laryngol 121:708-713

5. Shaha AR (2007) Routine laryngoscopy in thyroid surgery: a valuable adjunct. Surgery 142:865-866

6. Lang BH, Lee GC, Ng CP et al (2013) Evaluating the morbidity and efficacy of reoperative surgery in the central compartment for persistent/recurrent papillary thyroid carcinoma. World J Surg 37:2853-2859. doi:10.1007/s00268-013-2202-7

7. Wong KP, Lang BH, Chang YK et al (2015) Assessing the validity of transcutaneous laryngeal ultrasonography (TLUSG) after thyroidectomy: what factors matter? Ann Surg Oncol 22:1174-1780

8. Kandil E, Deniwar A, Noureldine SI et al (2016) Assessment of vocal fold function using transcutaneous laryngeal ultrasonography and flexible laryngoscopy. JAMA Otolaryngol Head Neck Surg 142:74-78

9. Wong KP, Woo JW, Youn YK et al (2014) The importance of sonographic landmarks by transcutaneous laryngeal ultrasonography in post-thyroidectomy vocal cord assessment. Surgery 156:1590-1596

10. Cheng SP, Lee JJ, Liu TP et al (2012) Preoperative ultrasonography assessment of vocal cord movement during thyroid and parathyroid surgery. World J Surg 36:2509-2515. doi:10.1007/ s00268-012-1674-1

11. Wang CP, Chen TC, Yang TL et al (2012) Transcutaneous ultrasound for evaluation of vocal fold movement in patients with thyroid disease. Eur J Radiol 81:e288-e291

12. Carneiro-Pla D, Miller BS, Wilhelm SM et al (2014) Feasibility of surgeon-performed transcutaneous vocal cord ultrasonography in identifying vocal cord mobility: a multi-institutional experience. Surgery 156:1597-1602

13. Carneiro-Pla D, Solorzano CC, Wilhelm SM (2016) Impact of vocal cord ultrasonography on endocrine surgery practices. Surgery 159:58-64

14. Borel F, Delemazure AS, Espitalier F et al (2016) Transcutaneous ultrasonography in early postoperative diagnosis of vocal cord palsy after total thyroidectomy. World J Surg 40:665-671. doi:10.1007/s00268-015-3393-x

15. Kocak S, Aydintug S, Ozbas S et al (1999) Evaluation of vocal cord function after thyroid surgery. Eur J Surg 165:183-186

16. Ooi LL (1992) B-mode real-time ultrasound assessment of vocal cord function in recurrent laryngeal nerve palsy. Ann Acad Med Singapore 21:214-216

17. Sidhu S, Stanton R, Shahidi S et al (2001) Initial experience of vocal cord evaluation using grey-scale, real-time, B-mode ultrasound. ANZ J Surg 71:737-739

18. Tsui PH, Wan YL, Chen CK (2012) Ultrasound imaging of the larynx and vocal fold: recent applications and developments. Curr Opin Otolaryngol Head Neck Surg 20:437-442

19. Wong KP, Lang BH, Ng SH et al (2013) A prospective, assessorblind evaluation of surgeon-performed transcutaneous laryngeal ultrasonography in vocal cord examination before and after thyroidectomy. Surgery $154: 1158-1165$

20. Wong KP, Woo JW, Li JY et al (2016) Using transcutaneous laryngeal ultrasonography (TLUSG) to assess post-thyroidectomy patients' vocal cords: which maneuver best optimizes visualization and assessment accuracy? World J Surg 40:652-658. doi:10. 1007/s00268-015-3304-1

21. Wong KP, Lang BH, Lam S et al (2016) Determining the learning curve of transcutaneous laryngeal ultrasound in vocal cord assessment by CUSUM analysis of eight surgical residents: when to abandon laryngoscopy. World J Surg 40:659-664. doi:10. 1007/s00268-015-3348-2 
22. Woo JW, Shu H, Song RY et al (2016) A novel lateral-approach laryngeal ultrasonography for vocal cord evaluation. Surgery 159:52-57

23. Tokashiki R, Hiramatsu H, Tsukahara K et al (2007) A "fenestration approach" for arytenoid adduction through the thyroid ara combined with type I thyroplasty. Laryngoscope 117:1882-1887
24. Fukuhara T, Morisaki T, Kataoka H, et al (2017) Modifications to the fenestration approach for arytenoid adduction under local anesthesia. J Voice 31:490-494

25. Wu AP, Sulica L (2014) Diagnosis of vocal fold paresis: current opinion and practice. Laryngoscope 125:904-908 